\title{
ANTIBIOTICS IN SERBIAN HOUSEHOLDS: A SOURCE OF POTENTIAL HEALTH AND ENVIRONMENTAL THREATS?
}

\author{
Milica Paut Kusturica', Zdenko Tomić1, Zoran Bukumirić², Olga Horvat', Nebojša Pavlović1, Momir Mikov, \\ Ana Sabo ${ }^{1}$ \\ 'Department of Pharmacology, Toxicology and Clinical Pharmacology, Faculty of Medicine, University of Novi Sad, Novi Sad, Serbia \\ ${ }^{2}$ Institute of Medical Statistics and Informatics, Faculty of Medicine, University of Belgrade, Belgrade, Serbia
}

\section{SUMMARY}

Aim: Worldwide data indicate that antibiotics are frequently used inappropriately. The objective of this study was to investigate the extent of storage and wastage of antibacterial agents in households in Novi Sad, Serbia.

Methods: The study was performed in 8 months period (December 2011-July 2012) in households in Novi Sad, Serbia. The households were randomly selected from the telephone directory. The interviewer performed the survey visiting each household.

Results: The total number of antibacterial agents in the 383 surveyed households was 318 , constituting $7.3 \%$ of the total stored medications. From 383 families included in the study antibiotics were found in $178(46.5 \%)$. In $13(7.3 \%)$ families were found more than one pack of the same antibiotics. The median number of antibacterial agents per household was 1 (range 1-5). The most common antibacterial agents that were not in current use were cephalexin $(22.1 \%)$ and amoxicillin $(16.6 \%)$, followed by doxycycline $(11.4 \%)$, sulfamethoxazole/trimethoprim (11.4\%) and amoxicillin/clavulanic acid $(9.2 \%)$. The percentage of expired antibacterial agents was $20.8 \%$, while $85.2 \%$ were not currently in use.

Conclusion: Antibacterial agents were commonly encountered in Serbian households, and a relatively large percentage was wasted. Informational and educational activities aimed at improving the public knowledge about antimicrobials play the leading role in reducing imprudent use of antibiotics.

Key words: antibiotics, storage, wastage, Serbia, households

Address for correspondence: M. P. Kusturica, Faculty of Medicine, University of Novi Sad, Hajduk Veljkova 3, 21000 Novi Sad, Serbia. E-mail: milicapaut@yahoo.com

\section{INTRODUCTION}

Recent analysis has shown that Serbia belongs to countries with high consumption of antibiotics $(1,2)$. The Republic of Serbia is a South Eastern European country in socioeconomic transition and in the process of harmonization with health laws of the European Union. Serbia has been an independent state since 2004 and is one of the few countries in Europe which has not joined the European Surveillance of Antimicrobial Consumption (ESAC) project yet.

Worldwide data indicate that antibiotics are frequently used inappropriately (3). This inappropriate use may contribute to antibiotic resistance, which is reaching alarming levels in Southern and Eastern Europe (4). Disregarding the problem of antibiotic resistance leads not only to unfavourable medical consequences, but also to substantial ecological and economic consequences (5-8).

A limited number of surveys have been conducted around the world to explore the extent of antibiotic storage in households. The study conducted in Spain showed that the storage of antibiotics in households is an important factor which increases the cost, reduces the efficiency and decreases the quality of antibiotic treatment at the community level (9). Similar studies carried out in Russia and Palestine indicated that antibiotics were widely stocked among the general population and often used for self-medication $(10,11)$.

Level of antibiotics storage and wastage in households is a topic of great interest and such study has not been carried out in
Serbia. Therefore, the objective of this study was to investigate to what extent antimicrobials are stored and wasted in a sample of households in Novi Sad.

\section{MATERIALS AND METHODS}

This is an observational, cross-sectional study of the characteristics of storage and wastage of antibacterial agents in households in the city of Novi Sad, Serbia. To the best of our knowledge, this is the first study of this type in Serbia. The study protocol was approved by the Ethical Committee of the Faculty of Medicine in Novi Sad. The study was performed in eight months period (December 2011-July 2012) and involved a sample of 383 households in Novi Sad. Sample size was calculated according to results of a pilot study researching self-medication conducted in 2010 in 191 households in Novi Sad, Serbia, where percentage of drugs that were bought without prescription or consultation with physician was $46.8 \%$. Based on this result, a sample size necessary to estimate the proportion of drugs bought without prescription with $95 \%$ confidence interval and $5 \%$ precision was 383 households.

The White Pages telephone directory with listing of noncommercial telephone subscribers was used for sampling. Systematic random sampling was performed by choosing the first number by random and dialing every 30th until the sample of 
383 households willing to cooperate was reached. In total, 1,008 households were contacted (response rate 38.0\%). According to 2011 Census of population, households and dwellings in the Republic of Serbia, the number of households in Novi Sad is 115 294 , thus our sample include $0.33 \%$ of households. The survey was performed in Serbian language by a trained interviewer who informed the respondents about the aim of the study and asked for permission to visit them at home. Only the families willing to cooperate were included in this study. The respondents were Serbian speaking adults ( $\geq 18$ years of age) responsible for the home medicine cabinets. If the right person was not available, the interview was performed with another randomly selected Serbian-speaking adult in the household.

The study consisted of a personal insight into the inventory of drugs and antibiotics in households and interview. Questionnaire was pre-tested on a small sample of households to ensure satisfactory validity and clarity. The questions were of varied format: checklists and closed-ended questions. The first part of the questionnaire focused on questions about age of the interviewee, educational level of the interviewee, number of family members and their ages, presence of any family member with a chronic disease, and presence of any family member with an acute disease (in the last two weeks). The second section of the questionnaire included questions about total number of stored drugs including antibacterial agents, whether the drug was obtained with a prescription or not, expiry date of the drug, whether the drug is stored in original packaging or not, and where the drug is stored. The last section of the questionnaire completed by the researcher included therapeutic class and dosage form of stored drugs, and monetary value.

For the purpose of this study, antibacterial agents were defined as those listed under the J01 category of the Anatomical Therapeutic Chemical (ATC) Classification System. In this study, each drug was considered as a separate item. For example, amoxicillin $500 \mathrm{mg}$ capsules and amoxicillin $250 \mathrm{mg}$ suspension were counted as two different items.

Statistical analysis was performed with SPSS software (SPSS 15.0 for Windows, SPSS Inc., Chicago, IL, USA). Results were presented as frequency, percent and mean \pm standard deviation (SD). For parametric data of independent samples t-test was used to test differences between groups. For numeric data with non-normal distribution and ordinal data Mann-Whitney U test was used. Chi-square test was used to test differences between nominal data (frequencies). The relationships between parameters were evaluated by Pearson and Spearman correlation analysis according to the distribution of data. All $\mathrm{p}$ values less than 0.05 were considered significant.

\section{RESULTS}

The total number of drug items present in 383 households was 4,384 with an average of $11.4 \pm 5.8$ per household. 318 drug items belonged to J01 (antibacterials for systemic use) class, constituting approximately $7.3 \%$ of the total stored medications. The number of antibacterial drug items by number of households is shown in Table 1. Of the 383 families, $46.5 \%$ had at least one item belonging to J01 class stored at home. The average number of antibacterial drug items per household was $1.8 \pm 1.0$. The me-
Table 1. Number of antibacterial drug items by number of households

\begin{tabular}{|c|c|c|}
\hline $\begin{array}{c}\text { Number of antibacterial } \\
\text { agents stored }\end{array}$ & $\begin{array}{c}\text { Number of households } \\
(\mathbf{n}=\mathbf{3 8 3})\end{array}$ & $\%$ \\
\hline 0 & 205 & 53.5 \\
\hline 1 & 94 & 24.5 \\
\hline 2 & 45 & 11.7 \\
\hline 3 & 25 & 6.5 \\
\hline 4 & 11 & 2.9 \\
\hline 5 & 3 & 0.8 \\
\hline Total & 383 & 100.0 \\
\hline
\end{tabular}

dian number of antibiotics per household was 1 (range 1-5). In $13(7.3 \%)$ families more than one pack of the same antibiotics was found. The most common antibacterial agents encountered in households that were not in current use were cephalexin $(22.1 \%)$ and amoxicillin (16.6\%), followed by co-trimoxazole $(11.4 \%)$, doxycycline (11.4\%), and amoxicillin/clavulanic acid (9.2\%) (Table 2). Total number of 318 antibacterial items stored belonged to 21 different types of antibacterial agents.

From the total stored antibacterial drug items, 47 (14.8\%) were currently used, while even 271 (85.2\%) were leftovers from previous use or supplies for the future use. The most common dosage forms of stored antibacterial drug items were oral solid dosage forms 288 (90.9\%), followed by oral liquid dosage forms 30 (9.4\%). Antibacterial agents were usually acquired with prescription or recommendation of healthcare provider $(67.7 \%)$, while about a third of packages $(32.3 \%)$ were purchased at pharmacy without prescription or recommendation of doctor (usually based on the previous experience or as recommended by friend).

The demographic and socioeconomic characteristics of household members are shown in Table 3 based on the number of antibiotic stored. There is a significant correlation between the number of family members and the number of antibacterials per household $(p=0.014)$. Families with more members have more antibacterial agents stored. A significant relationship was also found between the number of total drugs in households and the number of antibacterial agents $(p<0.001)$, as well as the presence of acute disease and elderly in households and number of antibacterial agents $(p<0.001$ and $p=0.023$, respectively). Education as

Table 2. Ten most frequently encountered leftovers of antibacterial agents in households

\begin{tabular}{|l|l|c|c|}
\hline ATC code & Drug name & Number & $\%$ \\
\hline J01DB01 & Cefalexin & 60 & 22.1 \\
\hline J01CA04 & Amoxicillin & 45 & 16.6 \\
\hline J01EE01 & Co-trimoxazole & 31 & 11.4 \\
\hline J01AA02 & Doxycycline & 31 & 11.4 \\
\hline J01CR02 & Amoxicillin and enzyme inhibitor & 25 & 9.2 \\
\hline J01FA10 & Azithromycine & 16 & 5.9 \\
\hline J01MA02 & Ciprofloxacin & 16 & 5.2 \\
\hline J01CE02 & Phenoxymethylpenicilin & 12 & 4.4 \\
\hline J01CA01 & Ampicilin & 8 & 2.9 \\
\hline J01FA01 & Erythromycin & 4 & 1.5 \\
\hline
\end{tabular}


Table 3. Demographic and socioeconomic characteristics associated with antibacterial agents stored

\begin{tabular}{|c|c|c|c|}
\hline Variable & Households with antibacterial agents & Households with no antibacterial agents & $\mathrm{p}$ \\
\hline Family size & $2.9 \pm 1.1$ & $2.7 \pm 1.1$ & 0.042 \\
\hline \multicolumn{4}{|l|}{ Gender } \\
\hline Male & $33(18.5 \%)$ & $44(21.5 \%)$ & \multirow{2}{*}{0.476} \\
\hline Female & $145(81.5 \%)$ & $161(78.5 \%)$ & \\
\hline \multicolumn{4}{|l|}{ Elderly $\geq 65$ years } \\
\hline Yes & $13(7.3 \%)$ & $30(14.6 \%)$ & \multirow{2}{*}{0.023} \\
\hline No & $165(92.7 \%)$ & $175(85.4 \%)$ & \\
\hline \multicolumn{4}{|l|}{ Education } \\
\hline Elementary school & $9(5.1 \%)$ & $18(8.8 \%)$ & \multirow{4}{*}{0.214} \\
\hline Secondary school & $75(42.1 \%)$ & $94(45.9 \%)$ & \\
\hline Junior college & $10(5.6 \%)$ & $15(7.3 \%)$ & \\
\hline Degree & $84(47.2 \%)$ & $78(38.0 \%)$ & \\
\hline \multicolumn{4}{|l|}{ Occupation } \\
\hline Employed & $108(60.7 \%)$ & $106(51.7 \%)$ & \multirow{4}{*}{0.087} \\
\hline Unemployed & $31(17.4 \%)$ & $30(14.6 \%)$ & \\
\hline Student & $6(3.4 \%)$ & $12(5.9 \%)$ & \\
\hline Retiree & $33(18.5 \%)$ & $57(27.8 \%)$ & \\
\hline \multicolumn{4}{|l|}{ Children $\leq 12$ years } \\
\hline Yes & $69(38.8 \%)$ & $66(32.2 \%)$ & \multirow{2}{*}{0.18} \\
\hline No & $109(61.2 \%)$ & $139(67.8 \%)$ & \\
\hline Average number of drugs per household & $13.7 \pm 6.1$ & $9.5 \pm 4.7$ & $<0.001$ \\
\hline \multicolumn{4}{|l|}{ Chronic disease } \\
\hline Yes & $76(42.7 \%)$ & $101(50.0 \%)$ & \multirow{2}{*}{0.154} \\
\hline No & $102(57.3 \%)$ & $101(50.0 \%)$ & \\
\hline \multicolumn{4}{|l|}{ Acute disease } \\
\hline Yes & $50(28.1 \%)$ & $6(2.9 \%)$ & \multirow{2}{*}{$<0.001$} \\
\hline No & $128(71.9 \%)$ & $201(97.1 \%)$ & \\
\hline
\end{tabular}

well as employment did not influence the number of antibiotics in households ( $p=0.214$ and $p=0.087$, respectively).

Antibiotics were most commonly stored in specific place pharmacy cabinets $(132,74.2 \%)$ or in the refrigerator $(19,10.7 \%)$, while in 27 (15.2\%) households antibiotics were kept in nonspecific places inside the house. Around a quarter of antibacterial drugs were stored in inadequate places such as kitchen (40, 22.5\%) or bathroom $(8,4.5 \%)$. It was also found that most $(295,92.8 \%)$ of the antibacterial drug items were in their original container.

\section{DISCUSSION}

Although some efforts have been made to control antibiotic use in Serbia, it remains an important issue. Several factors could be addressed to explain this situation. One important reason is that distribution of antimicrobials was not regulated, and therefore almost all of oral antimicrobials were frequently available without prescription in private pharmacies since November 2011. Nowadays, these drugs are not easily accessible, but it is still possible to purchase antibiotics without prescription in some local private pharmacies. The second reason is the lack of updated national guidelines for antimicrobial use for primary care physicians. The third reason may be the only recent introduction of the system of continuous education of health professionals in Serbia.

The aim of our survey was to get insight into the extent of antibiotic storage and wastage in households in Novi Sad, Serbia. Results of our survey showed that antibacterial agents constituted $7.3 \%$ of the total stored medication. Despite the fact that antibiotics should be obtained only with prescription in Serbian pharmacies, these medications still represent considerable percentage of medications in home pharmacies. Comparing the results of similar studies, our result is substantially higher than that reported in Belgium (2\%), but also noticeably lower than that reported in Sudan (22\%), Iran (13.6\%), and Saudi Arabia (14.3\%) (12-15). Such difference might be a result of different health systems and health seeking habits, different ways of supplying and dispensing of antibacterial agents and different attitudes and knowledge about antibacterial agents among different cultures and countries.

The most common antibacterial agents encountered in households that were not in current use were cephalexin and amoxicillin, followed by co-trimoxazole, doxycycline and amoxicillin/clavulanic acid. The structure of antibiotics in households relatively 
fits the structure of antibiotics consumption in Serbia. The main difference includes cephalexin being the most frequently encountered antibiotic in households and the secondly most consumed antibiotic in Serbia, while amoxicillin is the most commonly used antibiotic according to the data of Medicines and Medical Devices Agency of Serbia (1). The reason for this discrepancy might be that people tended to buy cephalexin more often than amoxicillin for self-medication of potential more complicated infections in the future.

Several factors influence the widespread presence of antibiotics in surveyed Serbian households. First of all, if we take into account the fact that the research was conducted shortly after enforcement of laws restricting the purchase of antibiotics without medical prescription (November 2011), some antibiotics found in visited households could represent supplies for future self-medication. Second reason for the levels of storage of antibacterial drug items is patient compliance with recommended treatment. Death of the patient, change in prescription, repeated filling of prescriptions without assessing the amount at hand were identified as major reasons why medicines are no longer used and expire. Furthermore, patients do not see a reason for continuing medication following a therapy change by the doctor or after the subjective perception of an improvement of their conditions. Nonadherence can stem from deliberate action of the patient related to individuals' beliefs (intentional non-adherence) and from factors outside the conscious control of the medicine user (unintentional non-adherence) (16). Patients often forget to take medication or may be unable to afford a full course. They tend to consider antibiotics as antipyretics that treat symptoms and stop taking them as soon as they feel better, which produces leftovers (17). Keeping leftover medication for future use was another source of misuse, because these antibiotics are kept in uncontrolled conditions and potentially used later without a medical prescription. Several studies in the USA have demonstrated considerable self-medication with antibiotics obtained from leftovers from previous courses (18-21). To reduce self-medication with leftovers, prescribed antibiotics should not be dispensed according to the package size. The practice of dispensing exact numbers of antibiotic tablets in pharmacies as implemented in the UK, the Netherlands, the Czech Republic, and Israel as well as in the USA, could be promoted in other countries (22).

Patient noncompliance with recommended treatment and storing antibiotics for future use are two main reasons of the drugs wastage. Our survey performed in 2010 demonstrated that there is a large stock of unused and expired medications in Serbian households (23). According to findings of the survey, only $14.8 \%$ of antibiotics were in current use, thus is not surprising that one out of five antibacterial agents $(20.8 \%)$ had passed the expiry date. Such practices impose not only health risks, but also economic loss both at individual and national level. Furthermore, recent study conducted in South Backa district, including Novi Sad as a major city, reported that the most common method for disposal of medications in households is disposal in the garbage which raises concerns about environmental contamination (23). According to the regulations of the Republic of Serbia on pharmaceutical wastes, pharmacies are required to collect pharmaceutical wastes from citizens, but the big issue is who would take responsibility and continue to pay for the storage and destruction of the waste because both wholesalers and manufacturers avoid this obliga- tion. The collection of unused drugs from the public is in its infancy in Serbia, and responsibilities for the overall collection and storage of pharmaceutical waste are yet to be defined. The consequence of improper disposal is the presence of pharmaceuticals in groundwater, lakes, rivers, and even drinking water, which is a huge environmental problem that will continue to grow as the population expands and more medications are dispensed. The environmental significance and human health risk that it represents is hotly debated, and the true risk may not be known for years (24-26)

Studies performed in low-income countries have shown that the determinants of self-medication with antibiotics include the cost of medical consultation, low satisfaction with medical practitioners and misconceptions regarding the efficacy of antibiotics (27). Similar situation is in Serbia. In order to avoid not very easy way to reach chosen general practitioner (GP) in state owned primary practice, who can exclusively prescribe the medication, many people in Serbia are prone to self-medication. Other reasons include the high number of patients per one GP and time spent in clinics - usually several hours. The majority of patients are not willing to consult qualified medical personnel to obtain a proper diagnosis and prescription for their health condition. Although we did not interview the patients on their reasons for this behaviour, the commonly given reasons include no time to consult a doctor, crowded clinics, impatience and ignorance of patients (28). On the other hand, doctors who work in private clinics are much more easily accessible, but only a small number of people can afford it.

In this study, the number of antibacterial agents stored in households was significantly associated with family size and number of total drugs stored. These results were anticipated since large families would be expected to consume more medications including antibacterial agents. A significant relationship found between the presence of acute disease and number of antibacterial agents was also expected, since acute diseases are mostly treated with antibacterial agents.

Our study has several limitations. First limitation is relatively small sample of investigated households. Secondly, Novi Sad is a university town with a large proportion of higher educated people, so generalization for other areas of Serbia should be done with caution. Another limitation is that was not possible to monitor the actual compliance use with the dosing regimen. Nevertheless, our study is important to underscore the need for educational efforts about antibiotic use. Furthermore, our study also provides a basis for future research on the problem of nonadherence to antibiotics among Serbian people as well as on accessibility and reliability of the medical information sources regarding antimicrobial agents.

According to the findings of this survey, patients represent a significant source of antibiotic misuse in the community. Nevertheless, inappropriate use of antibiotics is not exclusively a Serbian issue, developing countries are much more affected. Despite the enforcement of the law regulating the sale of antibiotics, antibacterial agents were commonly encountered in Serbian households, and a relatively large percentage was wasted. To reduce self-medication and misuse of antibiotics to greater extent, educational programmes targeting both healthcare professionals and consumers are urgently needed. A strong cooperation between healthcare providers, including researchers and consumers, is the real key to success. 


\section{Acknowledgement}

This work was supported by the Ministry of Education, Science and Technological Development, Republic of Serbia, project No. 41012.

\section{Conflicts of Interest}

None declared

\section{REFERENCES}

1. Trade and consumption of the medicinal products - Annual reports 2011 [Internet]. Belgrade: Medicines and Medical Devices Agency of Serbia; 2012 [cited 2013 Aug 12]. Available from: http://www.alims.gov.rs/ ciril/o-agenciji/publikacije/ppl2012. (In Serbian.)

2. Horvat O. Antibiotic consumption and antimicrobial resistance in the South Backa District [dissertation]. Novi Sad: University of Novi Sad; 2008. (In Serbian.)

3. Marlière GL, Ferraz MB, dos Santos JQ. Antibiotic consumption patterns and drug leftovers in 6000 Brazilian households. Adv Ther. 2000 Jan-Feb;17(1):32-44.

4. Goossens H, Ferech M, Vander Stichele R, Elseviers M; ESAC Project Group. Outpatient antibiotic use in Europe and association with resistance: a cross-national database study. Lancet. 2005 Feb 12-18;365(9459):57987.

5. Levy SB. Antibiotic resistance: an ecological imbalance. Ciba Found Symp. 1997;207:1-9; discussion 9-14.

6. Liu YC, Huang WK, Huang TS, Kunin CM. Inappropriate use of antibiotics and the risk for delayed admission and masked diagnosis of infectious diseases: a lesson from Taiwan. Arch Intern Med. 2001 Oct 22;161(19):2366-70.

7. Eandi M, Zara GP. Economic impact of resistance in the community. Int J Clin Pract Suppl. 1998 Jun;95:27-38.

8. Hellinger WC. Confronting the problem of increasing antibiotic resistance. South Med J. 2000 Sep;93(9):842-8

9. Orero A, González J, Prieto J; URANO Study Group. Antibiotics in Spanish households. Medical and socioeconomic implications. Med Clin (Barc). 1997 Dec 6;109(20):782-5. (In Spanish.)

10. Stratchounski LS, Andreeva IV, Ratchina SA, Galkin DV, Petrotchenkova NA, Demin AA, et al. The inventory of antibiotics in Russian home medicine cabinets. Clin Infect Dis. 2003 Aug 15;37(4):498-505.

11. Sawalha A. Extent of storage and wastage of antibacterial agents in Palestinian households. Pharm World Sci. 2010 Aug;32(4):530-5.

12. De Bolle L, Mehuys E, Adriaens E, Remon JP, Van Bortel L, Christiaens T. Home medication cabinets and self-medication: a source of potential health threats? Ann Pharmacother. 2008 Apr;42(4):572-9.

13. Yousif MA. In-home drug storage and utilization habits: a Sudanese study. East Mediterr Health J. 2002 Mar-May;8(2-3):422-31.

14. Zargarzadeh AH, Tavakoli N, Hassanzadeh A. A survey on the extent of medication storage and wastage in urban Iranian households. Clin Ther. 2005 Jun;27(6):970-8.
15. Abou-Auda HS. An economic assessment of the extent of medication use and wastage among families in Saudi Arabia and Arabian Gulf countries. Clin Ther. 2003 Apr;25(4):1276-92.

16. Vogler S, Leopold C, Zuidberg C, Habl C. Medicines discarded in household garbage: analysis of a pharmaceutical waste sample in Vienna. J Pharm Policy Pract. 2014 Jun 11;7:6.

17. Carlet J, Jarlier V, Harbarth S, Voss A, Goossens H, Pittet D; Participants of the 3rd World Healthcare-Associated Infections Forum. Ready for a world without antibiotics? The Pensières Antibiotic Resistance Call to Action. Antimicrob Resist Infect Control. 2012 Feb 14;1(1):11.

18. Mainous AG 3rd, Cheng AY, Garr RC, Tilley BC, Everett CJ, McKee MD. Nonprescribed antimicrobial drugs in Latino community, South Carolina. Emerg Infect Dis. 2005 Jun;11(6):883-8.

19. Richman PB, Garra G, Eskin B, Nashed AH, Cody R. Oral antibiotic use without consulting a physician: a survey of ED patients. Am J Emerg Med. 2001 Jan;19(1):57-60.

20. McKee MD, Mills L, Mainous AG 3rd. Antibiotic use for the treatment of upper respiratory infections in a diverse community. J Fam Pract. 1999 Dec;48(12):993-6.

21. Vanden Eng J, Marcus R, Hadler JL, Imhoff B, Vugia DJ, Cieslak PR, et al. Consumer attitudes and use of antibiotics. Emerg Infect Dis. 2003 Sep;9(9):1128-35.

22. Grigoryan L, Burgerhof JG, Degener JE, Deschepper R, Lundborg CS, Monnet DL, et al.; Self-Medication with Antibiotics and Resistance (SAR) Consortium. Determinants of self-medication with antibiotics in Europe: the impact of beliefs, country wealth and the healthcare system. J Antimicrob Chemother. 2008 May;61(5):1172-9.

23. Kusturica MP, Sabo A, Tomic Z, Horvat O, Solak Z. Storage and disposa of unused medications: knowledge, behavior, and attitudes among Serbian people. Int J Clin Pharm. 2012 Aug;34(4):604-10.

24. Daughton CG. Cradle-to-cradle stewardship of drugs for minimizing their environmental disposition while promoting human health. II. Drug disposal, waste reduction, and future directions. Environ Health Perspect. 2003 May;111(5):775-85.

25. Jones OA, Voulvoulis N, Lester JN. Potential impact of pharmaceuticals on environmental health. Bull World Health Organ. 2003;81(10):768-9.

26. Schwab BW, Hayes EP, Fiori JM, Mastrocco FJ, Roden NM, Cragin D, et al. Human pharmaceuticals in US surface waters: a human health risk assessment. Regul Toxicol Pharmacol. 2005 Aug;42(3):296-312.

27. Saradamma RD, Higginbotham N, Nichter M. Social factors influencing the acquisition of antibiotics without prescription in Kerala State, south India. Soc Sci Med. 2000 Mar;50(6):891-903.

28. Kvrgić M, Kvrgić V. Self-medication with antibiotics among adults in Serbia. Medicina danas. 2011;10(7-9):294-7. (In Serbian.)

Received September 8, 2014 Accepted in revised form January 15, 2015 